\title{
A rapid minor groove binder PCR method for distinguishing the vaccine strain Brucella abortus 104M
}

Wenlong Nan ${ }^{1}$, Lide Qin ${ }^{1}$, Yong Wang ${ }^{1,2}$, Yueyong Zhang ${ }^{1}$, Pengfei Tan ${ }^{1,2}$, Yuqi Chen ${ }^{4}$, Kairong Mao ${ }^{3}$ and Yiping Chen $^{*^{*}}$ (D)

\begin{abstract}
Background: Brucellosis is a widespread zoonotic disease caused by Gram-negative Brucella bacteria. Immunisation with attenuated vaccine is an effective method of prevention, but it can interfere with diagnosis. Live, attenuated Brucella abortus strain 104M has been used for the prevention of human brucellosis in China since 1965. However, at present, no fast and reliable method exists that can distinguish this strain from field strains. Single nucleotide polymorphism (SNP)-based assays offer a new approach for such discrimination. SNP-based minor groove binder (MGB) and Cycleave assays have been used for rapid identification of four Brucella vaccine strains (B. abortus strains S19, A19 and RB51, and B. melitensis Rev1). The main objective of this study was to develop a PCR assay for rapid and specific detection of strain 104M.
\end{abstract}

Results: We developed a SNP-based MGB PCR assay that could successfully distinguish strain 104M from 18 representative strains of Brucella (B. abortus biovars 1, 2, 3, 4, 5, 6, 7 and 9, B. melitensis biovars 1, 2 and 3, B. suis biovars 1, 2, 3 and 4, B. canis, B. neotomae, and B. ovis), four Brucella vaccine strains (A19, S19, S2, M5), and 55 Brucella clinical field strains. The assay gave a negative reaction with four non-Brucella species (Escherichia coli, Pasteurella multocida, Streptococcus suis and Pseudomonas aeruginosa). The minimum sensitivity of the assay, evaluated using 10-fold dilutions of chromosomal DNA, was $220 \mathrm{fg}$ for the $104 \mathrm{M}$ strain and $76 \mathrm{fg}$ for the single non-104M Brucella strain tested (B. abortus A19). The assay was also reproducible (intra- and inter-assay coefficients of variation $=0.006-0.022$ and $0.012-0.044$, respectively).

Conclusions: A SNP-based MGB PCR assay was developed that could straightforwardly and unambiguously distinguish B. abortus vaccine strain 104M from non-104M Brucella strains. Compared to the classical isolation and identification approaches of bacteriology, this real-time PCR assay has substantial advantages in terms of simplicity and speed, and also reduces potential exposure to live Brucella. The assay developed is therefore a simple, rapid, sensitive, and specific tool for brucellosis diagnosis and control.

Keywords: Brucellosis, Brucella abortus, Minor groove binder, SNP-based assay

\section{Background}

Brucellosis is a widespread zoonotic disease caused by various Gram-negative Brucella bacterial species that damages human health and results in considerable economic losses. Annually, more than 500,000 new human brucellosis cases are reported worldwide [1], and

\footnotetext{
*Correspondence: cyp777@163.com

'Laboratory of Diagnositics Development, China Animal Health and

Epidemiology Center, 369 Nanjing Road, Qingdao, Shandong 266032, China

Full list of author information is available at the end of the article
}

cases have increased rapidly over the last decade in all provinces in China [2]. Human brucellosis is transmitted by eating contaminated food products of animal origin and via direct animal contact [2], and although rarely fatal, it can be severely debilitating and disabling [3].

For over a century, vaccination and the culling of animals has been performed to control this disease [4-6]. In China, live attenuated Brucella strains are widely used for the prevention and control of brucellosis, including Brucella abortus strain A19 in cattle, B. suis S2 used in 
swine, and B. melitensis M5 in sheep and goat. In addition, live, attenuated $B$. abortus 104M has been adopted as a vaccine for use in humans since 1965. This strain, which was first isolated from the foetus of an aborted cow in the former Soviet republic in 1950, exhibits low virulence, high stability and high immunoantigenicity [7].

However, since it is a live attenuated strain, vaccination with $104 \mathrm{M}$ may cause vaccine-related cases of brucellosis, and it may be difficult to differentiate between a vaccine response and a natural infection, which complicates diagnosis. At present, a rapid and reliable method for distinguishing 104M from field strains is not available. The main objective of this study was to develop a PCR assay for rapid and specific detection of 104M.

\section{Methods}

\section{Strains and DNA extraction}

Brucella strains used in the present study are listed in Table 1. These comprised 18 representative strains of Brucella species and biovars, five Brucella vaccine strains, and 55 Brucella field strains. In addition, four non-target organisms (Escherichia coli K99, Pasteurella multocida C48-1, Pseudomonas aeruginosa DI-1, and Streptococcus suis ST171) were included. Brucella strains were cultured on tryptose agar at $37{ }^{\circ} \mathrm{C}$ with $5-10 \% \mathrm{CO}_{2}$ when required for $48-72 \mathrm{~h}$ in a biosafety level 3equipped laboratory. Bacteria were then washed with normal saline containing $0.5 \%$ formaldehyde, and inactivated at $37{ }^{\circ} \mathrm{C}$ for $24 \mathrm{~h}$. The four non-Brucella species were cultivated as described previously [8], and harvested and inactivated as described above. Unless specified, genomic DNA was extracted with the QIAamp DNA mini kit according to the manufacturer's instructions (Qiagen GmbH., D40724 Hilden).

\section{Minor groove binder (MGB) PCR}

In this real-time PCR assay, a pair of short TaqMan 5' labelled, 3'- MGB probes defining the single nucleotide polymorphism (SNP) were used to interrogate the 104M strain and non-104 M Brucella strains. Use of the MGB protein raises the melting temperature of probes meaning that a single base mismatch causes more destabilisation than would be the case with a longer probe [9]. This facilitates accurate SNP detection. For distinguishing B. abortus $104 \mathrm{M}$, the SNP $\mathrm{C}_{228}-\mathrm{T}_{228}$ in NL70_10085 was selected. This SNP was identified by comparison of the $B$. abortus $104 \mathrm{M}$ draft genomic sequence with the sequences of $B$. abortus 9-941, B. melitensis M28, B. suis S1330, B. canis ATCC 23365, and B. ovis ATCC 25840, $B$. pinnipedialis B2/94, B. microti CCM 4915. One set of primers and probes was designed based on this SNP (Table 2).
The assay was performed using the TransStart Green qPCR SuperMix kit (TransGen Biotech Co., Beijing, China) in a reaction volume of $25 \mu \mathrm{L}$ containing a reaction mixture volume of $12.5 \mu \mathrm{L}$ with the working concentrations of primers and probes listed in Table 2, together with the DNA template $(2 \mu \mathrm{L})$. For detection of the $104 \mathrm{M}$ strain, the VAC probe was labelled with 6carboxyfluorescein (FAM) at the $5^{\prime}$-end and MGB eclipse at the 3'-end. For detection of non-104 M Brucella strains, the NON probe was labelled with the fluorophore 4,7,2' -trichloro-7' -phenyl-6-carboxyfluorescein (VIC) at the $5^{\prime}$-end and MGB eclipse at the 3 ' -end.

PCR cycling parameters were as follows: $95{ }^{\circ} \mathrm{C}$ for $3 \mathrm{~min}$, followed by 40 cycles of $95{ }^{\circ} \mathrm{C}$ for $5 \mathrm{~s}, 56{ }^{\circ} \mathrm{C}$ for $10 \mathrm{~s}$, and $72{ }^{\circ} \mathrm{C}$ for $10 \mathrm{~s}$. Amplification was performed using the Bio-Rad MiniOpticon system (Bio-Rad Laboratories, Inc., Hercules, CA).

\section{Sensitivity, specificity, and reproducibility}

For assay sensitivity tests, the minimum detection limit of MGB PCR was evaluated using 10-fold serial dilutions of genomic DNA from B. abortus 104M for FAM fluorescence, and B. abortus A19 for VIC fluorescence. Each dilution was included in the assay to determine the minimum discriminatory amount of genomic DNA detected in the assay.

For assay specificity tests, we evaluated whether MGB PCR could distinguish the 104M strain from common species and other vaccine strains of Brucella using the representative and vaccine Brucella strains listed in Table 1. These strains included almost all common species and biovars of Brucella and the vaccine strains currently used in China. The four non-Brucella spp. (Escherichia coli K99, Pasteurella multocida C48-1, Streptococcus suis ST171, and Pseudomonas aeruginosa DI-1) were also tested.

Assay reproducibility was determined by calculating the intra- and inter-assay coefficients of variation $(\mathrm{CV})$, using at least three replicates of each of the 10-fold serial dilutions of genomic DNA to generate a standard curve. The efficiency of the assay was determined using the following calculation: Efficiency $=10(-1 /$ slope $)-1$.

\section{Detection of clinical field strains}

A further 55 Brucella spp. field isolates (see Table 1) that were isolated from different animal species and areas, identified and provided by China Veterinary Culture Collection Centre were also tested.

\section{Results}

Assay sensitivity

Using 10-fold serial dilutions of B. abortus 104M genomic DNA ranging from $1.1 \mathrm{ng} / \mu \mathrm{L}$ to $0.11 \mathrm{fg} / \mu \mathrm{L}$, the minimum discriminatory sensitivity for detection of 
Table 1 Brucella spp. strains used in the present study

\begin{tabular}{|c|c|c|c|c|}
\hline Species (biovar) & Strain & Type & Host & Region \\
\hline B. abortus (1) & A544 (CVCC790, ATCC23448) & Reference strain & Bovine & United Kingdom \\
\hline B. abortus (2) & 86/8/59 (CVCC12, ATCC23449) & Reference strain & Bovine & United Kingdom \\
\hline B. abortus (3) & Tulya (CVCC13, ATCC23450) & Reference strain & Bovine & United Kingdom \\
\hline B. abortus (4) & 292 (CVCC16, ATCC23451) & Reference strain & Bovine & United Kingdom \\
\hline B. abortus (5) & B3196 (CVCC14, ATCC23452) & Reference strain & Bovine & United Kingdom \\
\hline B. abortus (6) & 870 (CVCC17, ATCC23453) & Reference strain & Bovine & United Kingdom \\
\hline B. abortus (7) & 63/75 (CVCC15, ATCC23454) & Reference strain & Bovine & United Kingdom \\
\hline B. abortus (9) & C68 (CVCC11, ATCC23455) & Reference strain & Bovine & United Kingdom \\
\hline B. abortus (4) & C72-62 (CVCC887) & Field strain & Bovine & Inner Mongolia \\
\hline B. abortus (4) & C72-63 (CVCC888) & Field strain & Bovine & Inner Mongolia \\
\hline B. abortus (4) & C72-61 (CVCC886) & Field strain & Bovine & Inner Mongolia \\
\hline B. abortus (Unknown) & SHDeer-74 (CVCC780) & Field strain & Cervine & Shanghai \\
\hline B. abortus (Unknown) & C72-387 (CVCC785) & Field strain & Bovine & Heilongjiang \\
\hline B. abortus (Unknown) & C72-10 (CVCC786) & Field strain & Bovine & Heilongjiang \\
\hline B. abortus (Unknown) & 2308 (CVCC788) & Field strain & Bovine & Heilongjiang \\
\hline B. abortus (Unknown) & HBCow-1 (CVCC2408) & Field strain & Bovine & Hubei \\
\hline B. abortus (Unknown) & HBCow-2 (CVCC2409) & Field strain & Bovine & Hubei \\
\hline B. abortus (Unknown) & C72-12 (CVCC3621) & Field strain & Bovine & Heilongjiang \\
\hline B. abortus (Unknown) & C72-8401 (CVCC3622) & Field strain & Bovine & Inner Mongolia \\
\hline B. abortus (Unknown) & C72-8403 (CVCC3623) & Field strain & Bovine & Inner Mongolia \\
\hline B. abortus (Unknown) & NMCow-2 (CVCC3635) & Field strain & Bovine & Inner Mongolia \\
\hline B. melitensis (1) & 16 M (CVCC70002, ATCC23456) & Reference strain & Caprine & United Kingdom \\
\hline B. melitensis (2) & 63/9 (CVCC21, ATCC23457) & Reference strain & Caprine & United Kingdom \\
\hline B. melitensis (3) & Ether (CVCC20, ATCC23458) & Reference strain & Caprine & United Kingdom \\
\hline B. melitensis (1) & Goat-901 (CVCC3627) & Field strain & Caprine & Inner Mongolia \\
\hline B. melitensis (Unknown) & CVCC3620 & Field strain & Unknown & Inner Mongolia \\
\hline B. melitensis (Unknown) & C71-1257 (CVCC928) & Field strain & Caprine & Inner Mongolia \\
\hline B. melitensis (Unknown) & C71-13 (CVCC929) & Field strain & Caprine & Inner Mongolia \\
\hline B. melitensis (Unknown) & C71-35 (CVCC936) & Field strain & Ovine & Qinghai \\
\hline B. melitensis (Unknown) & C71-44 (CVCC938) & Field strain & Caprine & Xinjiang \\
\hline B. melitensis (Unknown) & Goat-963 (CVCC952) & Field strain & Caprine & Inner Mongolia \\
\hline B. melitensis (Unknown) & M54-8 (CVCC3624) & Field strain & Ovine & Qinghai \\
\hline B. melitensis (Unknown) & Goat-866 (CVCC3625) & Field strain & Caprine & Inner Mongolia \\
\hline B. melitensis (Unknown) & Goat-872 (CVCC3626) & Field strain & Caprine & Inner Mongolia \\
\hline B. melitensis (Unknown) & Goat-865 (CVCC3628) & Field strain & Caprine & Inner Mongolia \\
\hline B. suis (1) & S1330 (CVCC70524, ATCC23444) & Reference strain & Porcine & United Kingdom \\
\hline B. suis (2) & Thomsen (CVCC22, ATCC23445) & Reference strain & Porcine & United Kingdom \\
\hline B. suis (3) & 686 (CVCC23, ATCC23446) & Reference strain & Porcine & United Kingdom \\
\hline B. suis (4) & 40 (CVCC24, ATCC23447) & Reference strain & Porcine & United Kingdom \\
\hline B. suis (3) & KP6 (CVCC3651) & Field strain & Porcine & Guangdong \\
\hline B. suis (3) & ZC5 (CVCC3653) & Field strain & Porcine & Guangdong \\
\hline B. suis (3) & ZC1 (CVCC3655) & Field strain & Porcine & Guangdong \\
\hline B. suis (3) & ZC6 (CVCC3649) & Field strain & Porcine & Guangdong \\
\hline B. suis (3) & KP1 (CVCC3658) & Field strain & Porcine & Guangdong \\
\hline B. suis (3) & KP2 (CVCC3659) & Field strain & Porcine & Guangdong \\
\hline B. suis (3) & KP3 (CVCC3660) & Field strain & Porcine & Guangdong \\
\hline
\end{tabular}


Table 1 Brucella spp. strains used in the present study (Continued)

\begin{tabular}{|c|c|c|c|c|}
\hline Species (biovar) & Strain & Type & Host & Region \\
\hline B. suis (3) & KP5 (CVCC3661) & Field strain & Porcine & Guangdong \\
\hline B. suis (3) & HNPig-1 (CVCC3662) & Field strain & Porcine & Hainan \\
\hline B. suis (3) & HNPig-2 (CVCC3663) & Field strain & Porcine & Hainan \\
\hline B. suis (Unknown) & BS4 (CVCC1072) & Field strain & Porcine & Russian \\
\hline B. suis (Unknown) & C73-5 (CVCC1080) & Field strain & Porcine & Guangxi \\
\hline B. suis (Unknown) & C73-10 (CVCC1083) & Field strain & Porcine & Guangxi \\
\hline B. suis (Unknown) & C73-11 (CVCC1084) & Field strain & Porcine & Guangxi \\
\hline B. suis (Unknown) & C73-13 (CVCC1085) & Field strain & Porcine & Guangxi \\
\hline B. suis (Unknown) & C73-23 (CVCC1089) & Field strain & Porcine & Guangxi \\
\hline B. suis (Unknown) & C73-25 (CVCC1091) & Field strain & Porcine & Guangxi \\
\hline B. suis (Unknown) & C73-26 (CVCC1092) & Field strain & Porcine & Guangxi \\
\hline B. suis (Unknown) & Br.63/3 (CVCC3639) & Field strain & Unknown & United Kingdom \\
\hline B. suis (Unknown) & Br.63/142 (CVCC3640) & Field strain & Unknown & United Kingdom \\
\hline B. suis (Unknown) & Br.86/27 (CVCC3641) & Field strain & Unknown & United Kingdom \\
\hline B. suis (Unknown) & Br.63/62 (CVCC3642) & Field strain & Unknown & United Kingdom \\
\hline B. suis (Unknown) & Br.79/224 (CVCC3643) & Field strain & Unknown & United Kingdom \\
\hline B. suis (Unknown) & Br.Thomsen1720 (CVCC3644) & Field strain & Unknown & United Kingdom \\
\hline B. suis (Unknown) & Br.Thomsen5 (CVCC3645) & Field strain & Unknown & United Kingdom \\
\hline B. suis (Unknown) & Br.63/225 (CVCC3646) & Field strain & Unknown & United Kingdom \\
\hline B. suis (Unknown) & Br.63/32 (CVCC3647) & Field strain & Unknown & United Kingdom \\
\hline B. suis (Unknown) & Br.64/24 (CVCC3648) & Field strain & Unknown & United Kingdom \\
\hline B. suis (Unknown) & ZC2 (CVCC3656) & Field strain & Porcine & Guangdong \\
\hline B. suis (Unknown) & ZC3 (CVCC3657) & Field strain & Porcine & Guangdong \\
\hline B. suis (Unknown) & DF1 (CVCC3654) & Field strain & Porcine & Guangdong \\
\hline B. suis (Unknown) & SD1 (CVCC3652) & Field strain & Porcine & Guangdong \\
\hline B. suis (Unknown) & ZC4 (CVCC3650) & Field strain & Porcine & Guangdong \\
\hline B. ovis & 63/290 (CVCC70015, ATCC25840) & Reference strain & Ovine & United Kingdom \\
\hline B. canis & RM6/66 (CVCC70701, ATCC23365) & Reference strain & Canine & United Kingdom \\
\hline B. canis & KP4 (CVCC3664) & Field strain & Canine & Guangdong \\
\hline B. neotomae & 5 K33 (CVCC70721, ATCC23459) & Reference strain & Unknown & United Kingdom \\
\hline B. abortus (1) & A19 & Vaccine & - & - \\
\hline B. melitensis (1) & M5 & Vaccine & - & - \\
\hline B. abortus (Unknown) & $104 \mathrm{M}$ & Vaccine & - & - \\
\hline B. abortus (1) & S19 & Vaccine & - & - \\
\hline B. suis (1) & S2 & Vaccine & - & - \\
\hline
\end{tabular}

Strains were identified and provided by the China Veterinary Culture Collection Centre (CVCC) Unknown = unknown biovar or host

Table 2 Targets, primers and probes used for the MGB PCR assay with the associated working concentrations

\begin{tabular}{llll}
\hline Target (positon) & Gene description & Working concentration (nM) & Primer \\
\cline { 3 - 4 } & & Probe & F: CCGGAAGGCACCCTTTT (600) \\
\hline NL70_10085 (228) & molecular chaperone DnaK & VAC: CCGTCGITATGACGAT (160) & R: GATCCTTGTCCTTGGTGACCAT (600)
\end{tabular}

The position of the SNP within each target is shown in parentheses. The target SNP is shown in bold underlined font in both vaccine (VAC) and nonspecific (NON) probes 
$104 \mathrm{M}$-specific strains was $\sim 220 \mathrm{fg}$ per reaction for MGB PCR (Table 3). Similarly, using 10-fold serial dilutions of $B$. abortus A19 genomic DNA ranging from $3.8 \mathrm{ng} / \mu \mathrm{L}$ to $0.38 \mathrm{fg} / \mu \mathrm{L}$, the minimum discriminatory sensitivity for detection of non-104 M Brucella strains was $\sim 76 \mathrm{fg}$ per reaction for MGB PCR (Table 3 ). These results indicated that the assays were highly sensitive for the detection of 104M and non-104 M Brucella genomic DNA in a single reaction.

\section{Assay specificity}

For evaluating specificity, the representative and vaccine Brucella strains listed in Table 1 were tested using the MGB PCR method described. The results showed that 18 representative strains of Brucella (B. abortus biovars 1, 2, 3, 4, 5, 6, 7 and 9, B. melitensis biovars 1, 2 and 3, B. suis biovars 1, 2, 3 and 4, B. canis, B. neotomae and B. ovis), and four Brucella vaccine strains (A19, S19, S2, M5) gave strong VIC fluorescence and weak FAM fluorescence below the threshold detection level (Fig. 1a and b).

Only the $B$. abortus $104 \mathrm{M}$ vaccine strain gave strong FAM fluorescence and weak VIC fluorescence below the threshold detection level (Fig. 1a and b), indicating that the assay was $104 \mathrm{M}$-specific. All four non-Brucella species (Escherichia coli K99, Pasteurella multocida C48-1, Streptococcus suis ST171 and Pseudomonas aeruginosa DI-1) were negative for both FAM and VIC fluorescence. These results suggest the MGB PCR assay was highly capable of differentiating 104M from non-104 M Brucella isolates and non-Brucella strains.

\section{Assay reproducibility}

The standard curve generated using genomic DNA was linear over a wide range of dilutions $\left(R^{2}=0.997\right.$ and slope $=-3.645$ for FAM fluorescence; $R 2=0.982$ and slope $=-4.342$ for VIC fluorescence). The assay was reproducible, with intra-assay CVs ranging from 0.006 to 0.022 , and inter-assay CVs of 0.012 to 0.044 . The efficiency of the assay was $88.1 \%$ for FAM fluorescence and
$69.9 \%$ for VIC fluorescence. These figures were used to determine the threshold for detection.

\section{Detection of clinical field strains}

The results demonstrated strong VIC fluorescence and weak FAM fluorescence for all 55 Brucella spp. field isolates tested (Table 1), indicating that none were the $104 \mathrm{M}$ strain.

\section{Discussion}

The $B$. abortus vaccine strain $104 \mathrm{M}$ is a stable antigenic structure with low virulence and high immunogenicity, hence it has been used in China since 1965 to vaccinate cattle and humans against brucellosis. Because using a live vaccine may lead to severe pathogenic injury associated with allergy, the 104M strain was only recommended for high-risk populations in China [7], such as those at high risk due to their occupation [10]. The scratch vaccination method was used to introduce five billion bacteria, which achieved 90\% protection for a 12 month duration [7]. In some areas in China, vaccination intervention in humans had an obvious effect; the reported cases of brucellosis in the Arong Banner declined sharply by $84.17 \%$ from 2005 to 2006 following vaccination, and the morbidity rate of brucellosis declined from 34,732 per 100,000 to 5454 per 100,000 [11].

However, due to lack of serological differentiation, it is difficult to distinguish $104 \mathrm{M}$ by serological assay alone. The recent development of SNP-based real-time assays offers a new approach for overcoming this hurdle. SNPbased MGB and Cycleave assays have been used for rapid identification of four Brucella vaccine strains ( $B$. abortus strains S19, A19 and RB51, and B. melitensis Rev1) [12, 13].

In the present study, we developed a new MBG PCR assay that can successfully distinguish $104 \mathrm{M}$ strains from other bacterial strains, with a sensitivity of $220 \mathrm{fg}$, equating to around 60 cells. Furthermore, our MGB PCR assay can detect non-104 M Brucella strains in a single

Table 3 Mean quantification cycle $(C q)$ values resulting from MGB PCR ${ }^{a}$

\begin{tabular}{|c|c|c|c|c|c|}
\hline \multicolumn{3}{|c|}{ Detection of $104 \mathrm{M}$ genomic DNA } & \multicolumn{3}{|c|}{ Detection of A19 genomic DNA } \\
\hline Concentration & Cq of FAM & Cq of VIC & Concentration & Cq of FAM & $\mathrm{Cq}$ of $\mathrm{VIC}$ \\
\hline $1.1 \mathrm{ng} / \mu \mathrm{L}$ & 24.06 & NA & $3.8 \mathrm{ng} / \mu \mathrm{L}$ & NA & 17.49 \\
\hline $110 \mathrm{pg} / \mu \mathrm{L}$ & 27.20 & NA & $380 \mathrm{pg} / \mu \mathrm{L}$ & NA & 20.89 \\
\hline $11 \mathrm{pg} / \mu \mathrm{L}$ & 30.92 & NA & $38 \mathrm{pg} / \mu \mathrm{L}$ & NA & 24.39 \\
\hline $1.1 \mathrm{pg} / \mu \mathrm{L}$ & 35.27 & NA & $3.8 \mathrm{pg} / \mu \mathrm{L}$ & NA & 31.90 \\
\hline $110 \mathrm{fg} / \mu \mathrm{L}$ & 38.25 & NA & $380 \mathrm{fg} / \mu \mathrm{L}$ & NA & 34.69 \\
\hline $11 \mathrm{fg} / \mu \mathrm{L}$ & NA & NA & $38 \mathrm{fg} / \mu \mathrm{L}$ & NA & 38.11 \\
\hline $1.1 \mathrm{fg} / \mu \mathrm{L}$ & NA & NA & $3.8 \mathrm{fg} / \mu \mathrm{L}$ & NA & NA \\
\hline $0.11 \mathrm{fg} / \mu \mathrm{L}$ & NA & NA & $0.38 \mathrm{fg} / \mu \mathrm{L}$ & NA & NA \\
\hline
\end{tabular}

${ }^{\mathrm{a}} \mathrm{FAM}=$ 6-carboxyfluorescein; VIC = 4,7,2'-trichloro-7'-phenyl-6-carboxyfluorescein; NA = not applicable 

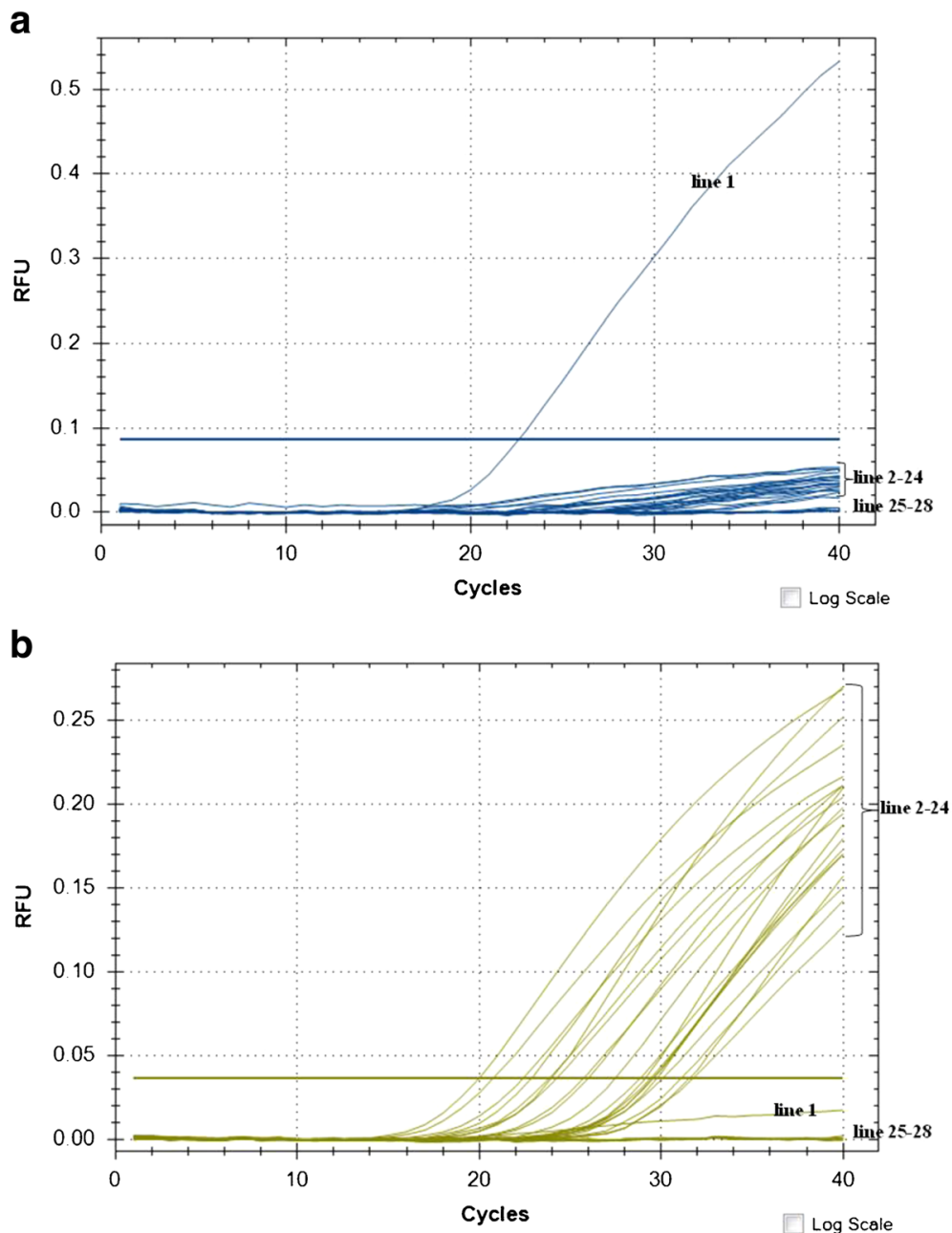

Fig. 1 Specificity of the MGB PCR assay using representative experiments for the detection of (a) FAM fluorescence and (b) VIC fluorescence. The following strains were subjected to amplification assays: Line 1, 104 M; Line 2 Brucella suis biovar 1 S1330; Line 3, B. suis biovar 2 Thomsen; Line 4, B. suis biovar 3686; Line 5, B. suis biovar 4 40; Line 6, B. abortus biovar 1 A544; Line 7, B. abortus biovar 2 86/8/59; Line 8, B. abortus biovar 3 Tulya; Line 9, B. abortus biovar 4292; Line 10, B. abortus biovar 5 B3196; Line 11, B. abortus biovar 6870; Line 12, B. abortus biovar 7 63/75; Line 13, B. abortus biovar 9 C68; Line 14, B. melitensis biovar 116 M; Line 15, B. melitensis biovar 2 63/9; Line 16, B. melitensis biovar 3442; Line 17, B. ovis 63/ 290; Line 18, B. canis RM6/66; Line 19, B. neotomae 5 K33; Line 20, S2; Line 21, S19; Line 22, A19; Line 23, M5; Line 24, S2; Line 25, Escherichia coli K99; Line 26, Pasteurella multocida C48-1; Line 27, Streptococcus suis ST171; Line 28, Pseudomonas aeruginosa DI-1

reaction with a sensitivity of $76 \mathrm{fg}$, equating to around 30 cells. This assay allows accurate and reliable discrimination of 104M and non-104 M Brucella strains from common species and biovars of Brucella, Brucella vaccines, and other bacterial strains. Our assay therefore provides a simple, rapid, sensitive, and specific tool for use in the control of brucellosis.

\section{Conclusions}

A SNP-based MGB PCR assay was developed that could straightforwardly and unambiguously distinguish B. abortus vaccine strain 104M. Results of our study indicate the assay allows accurate and reliable discrimination of 104M and non-104 M Brucella strains from common species and biovars of Brucella, Brucella vaccines, and other bacterial strains. The minimum detection limit of the assay was $220 \mathrm{fg}$ for strain $104 \mathrm{M}$ and $76 \mathrm{fg}$ for the single non-104 M Brucella strain tested. Compared to the classical isolation and identification approaches of bacteriology, this real-time PCR assay has substantial advantages in terms of simplicity and speed, and also reduces the potential for exposure to live Brucella. As real-time PCR instruments become more widely used in China, the approach will become widely applicable in routine diagnostics. The assay developed is therefore a simple, rapid, sensitive, and specific tool for brucellosis diagnosis and control. 


\section{Abbreviations}

B. abortus: Brucella abortus; B. canis: Brucella canis; B. melitensis: Brucella melitensis; B. neotomae: Brucella neotomae; B. ovis: Brucella ovis; $B$. suis: Brucella suis; FAM: 6-carboxyfluorescein; MGB: Minor groove binder; SNP: Single nucleotide polymorphism-based; VIC: 4,7,2'-trichloro-7'-phenyl-6carboxyfluorescein

\section{Acknowledgements}

Not applicable

\section{Funding}

This work was financially supported by the National Key Research and Development Program of China (No.2017YFF0208600).

\section{Availability of data and materials}

The datasets used and/or analysed during the current study are available from the corresponding author on reasonable request.

\section{Authors' contributions}

YPC and WN conceived and designed the experiment. WN and YW designed the set of primers and probes. PT cultured all the Brucella and non-Brucella species. WN, LQ, YW and YZ carried out the experiment, including preparation of the bacterial genomic samples, sensitivity assay, specificity assay, reproducibility assay and detection of clinical field strains. WN and YQC analyzed the data and wrote the manuscript. KM and YPC verified the validity and checked the results. All authors read and approved the final version of this manuscript

\section{Ethics approval and consent to participate}

Not Applicable

\section{Consent for publication}

Not Applicable

\section{Competing interests}

The authors declare that they have no competing interests.

\section{Publisher's Note}

Springer Nature remains neutral with regard to jurisdictional claims in published maps and institutional affiliations.

\section{Author details}

'Laboratory of Diagnositics Development, China Animal Health and Epidemiology Center, 369 Nanjing Road, Qingdao, Shandong 266032, China ${ }^{2}$ College of Veterinary Medicine, Yangzhou University, 12 East Wenhui Road, Yangzhou, Jiangsu 225009, China. ${ }^{3}$ China Institute of Veterinary Drug Control, 8 Zhongguanchun South Street, Beijing 100081, China. ${ }^{4}$ Xi'an Jiaotong-Liverpool University, 111 Ren'ai Road, Suzhou, Jiangsu Province 215123, China.

Received: 28 August 2017 Accepted: 16 January 2018

Published online: 24 January 2018

\section{References}

1. Atluri $V L$, Xavier MN, de Jong MF, den Hartigh $A B$, Tsolis RM. Interactions of the human pathogenic Brucella species with their hosts. Annu Rev Microbiol. 2011;65:523-41.

2. Yu D, Hui Y, Zai X, Xu J, Liang L, Wang B, et al. Comparative genomic analysis of Brucella abortus vaccine strain 104M reveals a set of candidate genes associated with its virulence attenuation[J]. Virulence. 2015;6:745-54

3. Perkins SD, Smither SJ, Atkins HS. Towards a Brucella vaccine for humans. FEMS Microbiol Rev. 2010:34:379-94.

4. Pappas G, Papadimitriou P, Akritidis N, Christou L, Tsianos EV. The new global map of human brucellosis. Lancet Infect Dis. 2006;6:91-9.

5. Corbel MJ. Brucellosis: an overview. Emerg Infect Dis. 1997:3:213-21.

6. Joint FAO/WHO expert committee on brucellosis. World Health Organ Tech Rep Ser 1986; 740:1-132; PMID: 3097967

7. Deqiu S, Donglou X, Jiming Y. Epidemiology and control of brucellosis in China. Vet Microbiol. 2002;90:165-82.

8. Huang QY, Wu R, Dong GX. Study of bacteriology. In: Lu CP, editor. veterinary microbiology. 3rd ed. Beijing: China agriculture press; 2001. p. 199-382. Chinese
9. Kutyavin IV, Lukhtanov EA, Gamper HB, Meyer RB. Oligonucleotides with conjugated dihydropyrroloindole tripeptides: base composition and backbone effects on hybridization. Nucleic Acids Res. 1997;25:3718-23.

10. Jing Z, Yan J, Fan W. Research progress of brucellosis vaccine. Chin J Zoonoses. 2016;32:188-99. (in Chinese)

11. Mi J, Han Y, Lin H, Li X, Ta N, Wei R, et al. Effect of the professional population intervention with the brucellosis bacteria vaccine for 5 years in Arong banner. Inner Mongolia Chin J Zoonoses. 2013;29:633-5. (in Chinese)

12. Gopaul KK, Sells J, Bricker BJ, Crasta OR, Whatmore AM. Rapid and reliable single nucleotide polymorphism-based differentiation of Brucella live vaccine strains from field strains. J Clin Microbiol. 2010:48:1461-4.

13. Nan W, Zhang $Y$, Tan $P, X u Z$, Chen $Y$, Mao K, et al. A rapid cycleave PCR method for distinguishing the vaccine strain Brucella abortus A19 in China. J Vet Diagn Investig. 2016;28:214-8.

\section{Submit your next manuscript to BioMed Central and we will help you at every step:}

- We accept pre-submission inquiries

- Our selector tool helps you to find the most relevant journal

- We provide round the clock customer support

- Convenient online submission

- Thorough peer review

- Inclusion in PubMed and all major indexing services

- Maximum visibility for your research

Submit your manuscript at www.biomedcentral.com/submit
Biomed Central 